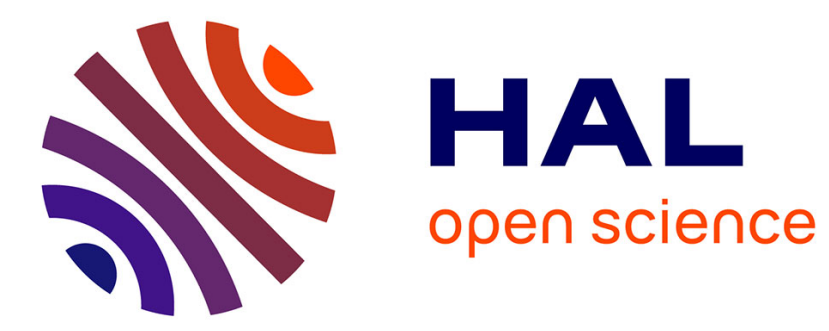

\title{
Listener evaluations of violins made from composites
} Tim Duerinck, Geerten Verberkmoes, Claudia Fritz, Marc Leman, Luc Nijs, Mathias Kersemans, Wim van Paepegem

\section{To cite this version:}

Tim Duerinck, Geerten Verberkmoes, Claudia Fritz, Marc Leman, Luc Nijs, et al.. Listener evaluations of violins made from composites. Journal of the Acoustical Society of America, 2020, 147 (4), pp.26472655. 10.1121/10.0001159 . hal-02937610

\section{HAL Id: hal-02937610 https://hal.science/hal-02937610}

Submitted on 11 Dec 2020

HAL is a multi-disciplinary open access archive for the deposit and dissemination of scientific research documents, whether they are published or not. The documents may come from teaching and research institutions in France or abroad, or from public or private research centers.
L'archive ouverte pluridisciplinaire HAL, est destinée au dépôt et à la diffusion de documents scientifiques de niveau recherche, publiés ou non, émanant des établissements d'enseignement et de recherche français ou étrangers, des laboratoires publics ou privés. 


\section{Listener evaluations of violins made from 2 composites. \\ 3}

4 Tim Duerinck ${ }^{1}$, Geerten Verberkmoes ${ }^{1}$, Claudia Fritz ${ }^{2}$, Marc Leman ${ }^{3}$, Luc Nijs ${ }^{3}$, Mathias

5 Kersemans $^{4}$ and Wim Van Paepegem ${ }^{4}$

$6{ }^{1}$ Instrument Making - School of Arts Gent KASK \& Royal Conservatory, Nederpolder 26, 9000

7 Ghent, Belgium

$8 \quad{ }^{2}$ Institut Jean le Rond d'Alembert, Sorbonne Université / CNRS, 4 place Jussieu, 75005 Paris, 9 France.

$10{ }^{3}$ Department of Art, music and theater sciences, Ghent University, Sint-Pietersnieuwstraat 41, B4

119000 Ghent, Belgium

$12{ }^{4}$ Department of materials, textiles and chemical engineering, Ghent University, Technologiepark

13 46, B-9052 Zwijnaarde, Belgium.

15 https://doi.org/10.1121/10.0001159

16 Published in JASA

17 (Received 9 December 2019; revised 6 March 2020; accepted 8 April 2020; published online 28 April 2020)

18 [Editor: Tamara Smyth] 
20 For centuries, wood, and more specifically spruce, has been the material of choice for violin 21 top plates. Lately, carbon fiber instruments have entered the market. Some studies show 22 that composite materials have potential advantages for making instruments (Damodaran A. 23 et al. (2015)). However, no studies exist that evaluate violins made of different composite 24 materials as judged by listeners. For this study, six prototype violins, differing only by the 25 material of the top plate, were manufactured in a controlled laboratory setting. The six 26 prototype violins were judged by experienced listeners in two double-blind experiments. In 27 contrast to popular opinion that violins made from carbon have or lack a specific sound 28 quality, the study provides insights in the diverse sounds and timbres violins from fiber29 reinforced polymers can create. It allows to investigate the links between the perception and 30 the variations in material properties of the soundboards. Additionally, as neither players

31 nor listeners are acquainted with these instruments, these results provide an interesting 32 view on what type of qualities of violin-like sounds are preferred by listeners. 


\section{INTRODUCTION}

34 The soundboard of a violin has, with few exceptions, always been made out of wood, more 35 specifically of high quality spruce (Picea Abies). However, due to environmental changes and 36 other factors, wood for music instruments is said to be depleting, becomes more expensive, but

37 also lowers in quality ${ }^{1}$. Meanwhile, the increase in use of technical composites such as carbon

38 fiber reinforced polymer (CFRP) and their qualities with regard to moisture stability and 39 durability, has generated research that investigates their material properties and compares them to $40 \operatorname{wood}^{2-4}$. Consequently, in recent years, research has resulted in prototypes and commercially 41 available instruments made from composites ${ }^{5-9}$. However, no comparative studies that assess the

42 sound of composite violins with the same design and setup under controlled conditions is found

43 in literature. Most studies are limited in this regard because the violins to be tested were 44 constructed independently from the research and can therefore vary in a number of attributes 45 unknown to the researcher, like the model, quality of the materials used, construction method or 46 setup ${ }^{10-14}$. In the present study, the influence of the soundboard material is our focus, as a 47 consequence, all other parameters are taken as similar as possible among the tested violins. Under 48 these conditions, we consider the following questions: How do these composite violins sound?

49 Which variations in the construction of the soundboard influence the volume and timbre of the 50 sound? What possible quality factors are more important to the listeners? What possibilities do 51 composite materials offer to expand on the violin's sonic palette as we know it today?

52 To answer these questions six composite violins were designed and built with top plates from

53 different materials. We ran two experiments with the instruments; the first consisted of an 54 evaluation task with 37 participants, the second of a selection task with 40 participants. In both 55 cases, we examined how experienced listeners judged the timbre of the instruments on a broad 
56 spectrum of possible qualities. We examined which instruments were favored, and why, in order

57 to shed light on what sound listeners prefer from such composite violin.

\section{CONSTRUCTION OF THE PROTOTYPE VIOLINS}

The goal was to build all violins identical except for the top plate, which was made from different materials between the violins. To achieve this goal, all prototype violins were constructed by the same luthier. A carbon fiber reinforced polymer (CFRP) produced by vacuum assisted resin transfer method (VARTM) was chosen as a quick and reliable way to produce the back, sides and neck in one piece in a consistent way (Video ${ }^{15}$ showing the production process on a cello). The soundboards were made either from a selection of four composite materials or from spruce, which was added as a reference material (Fig. 1):

The TwillC violin was produced twice (TwillCA and TwillCB) to check the consistency of the influence of the material and production methods on the sound of the violin. Together, these six prototypes give us a variety in material properties like higher damping (UDFlax), different degrees of anisotropy (TwillC \& UDC), and a low weight soundboard (Sandwich). The violin with a soundboard from Spruce serves as a benchmark material.

As the used composite materials have a higher longitudinal Young's modulus than wood, the 
78 plate. The bending stiffness of a plate is thought to be crucial to the sound of a wooden 79 instrument ${ }^{16}$, therefore it is taken as a guide to make these novel composite violins. Soundboards 80 of old conventional violins deform most often along the axis of the instrument ${ }^{17}$. Contemporary 81 luthiers therefore aim to make an arching stiff enough to be durable, without making it too stiff, 82 which is thought to be disadvantageous to the sound production of the violin ${ }^{16}$. As composite 83 materials offer a variety in anisotropy, the bending stiffness along the axis of the instrument 84 (D11) was chosen as the primary design criteria. The bending stiffness (or plate rigidities) are 85 derived from the ABD-Matrix of the Classical Laminate Theory. The required thickness for each 86 of these materials was calculated using the $\mathrm{eLamX}^{2}$ software package ${ }^{18}$. The composite 87 soundboards were produced by VARTM. More detailed information on the materials, model, and 88 production method are provided in Appendix and ${ }^{19}$. Weight of the soundboards, calculated 89 bending stiffness's D11 (along the axis/longitudinal), D22 (transversal/radial), D66 (shear) and 90 damping of the materials are provided in Table I. The plate rigidities show the variety in 91 anisotropy between the materials. The damping is an approximation derived from the measured Q 92 factor of the first frequency of flat beams which were made in our lab by VARTM (Appx). As 93 this damping value is dependent on the mode measured, the exact value could be misleading. 94 Therefore the damping is given as an approximation in relation to spruce (0), our benchmark 95 material.

The spruce soundboard was carved by a luthier using templates that match the arching of the

97 composite plates. This spruce soundboard was then given a thin clear oil varnish coating. The 98 soundboards were given a simplified sound hole design and were fitted with a conventional 99 spruce bass bar of high quality. The instruments were mounted with a high quality Aubert bridge 100 (Savarez $\left(\right.$ )), spruce soundpost, Wittner tailpiece, chinrest, and fine-tune pegs ${ }^{\circledR}$ (WITTNER® 
102 for E (D’Addario \& Company, Inc.@). A second independent luthier was then asked to examine

103 the instruments for any (accidental) differences in the set-up. In this way, a small difference (1

$104 \mathrm{~mm}$ ) in the placement of the bridge of the UDFlax violin was corrected.

\section{III. THE EVALUATION EXPERIMENT}

\section{A. Methodology}

107 Experienced listeners with relevant musical experience were invited to take part in the 108 experiment. The group of participants included (student) instrument makers, musicians, music 109 teachers and composers. Of the 37 listeners, 33 said that they play a music instrument on a 110 regular basis. Their experience ranged from 3 to 52 years of experience with an average of 15.1

111 years of playing a music instrument. In the weeks before the experiment, potential participants 112 were told that they would have to evaluate on an aural basis seven violins, of which at least one 113 was made of carbon and one made from flax fibers. This information was given to raise interest 114 and recruit a sufficient amount of experienced listeners. As a consequence, some of the recruited 115 listeners were familiar with the research subject (new materials for violins) yet they did not know 116 how many "new" instruments would be used in this test or if there would be one or multiple 117 instruments with a wooden soundboard and/or conventional violins, as a reference.

118 In the first listening test the members of the audience, rated the six violins individually on a 119 number of attributes. This method was chosen as it is a common way to judge instruments or 120 musicians in competitions, giving the test a high verisimilitude. For each violin, the attributes 121 were presented on a 8-point Likert scale between two opposite adjectives. Most invited 122 participants had Dutch as their mother tongue. As no study that uses Dutch words to describe the 
123 sound of violins was available in the literature, a common language had to be defined with the

124 participants. First a list of English words was compiled from scientific literature ${ }^{11,20}$. Secondly,

125 multiple listeners who would take part in the experiment were asked which words they would like

126 to use for judging violins in Dutch and English as well as how they would translate these words

127 between the two languages. Also the participants were asked how they would like to be

128 questioned. Through this method an expert audience negotiated and agreed on the meaning of

129 pairs of adjectives that could be understood as each other's opposite, with the Dutch translation in

130 brackets: warm (warm) - cold (koud), clear (helder) - dull (dof), loud (luid) - quiet (stil), soft

131 (zacht) - harsh (hard), open (open) - closed (gesloten), good (goed) - bad (slecht), nasal (nasaal)

132 - clear (helder), round (rond) - sharp (scherp), powerful (krachtig) - weak (zwak), rich (rijk) -

133 poor (arm), bright (briljant) - dim (glansloos). Although a unipolar scale is usually recommended

134 in this type of research ${ }^{20}$, the participants preferred a bipolar scale.

135 Participants could fill in the Likert scale for each presented pair of opposite adjectives, or tick a 136 box 'I don't know' (Appx). The listening test took place in a 98-seat concert hall at the Royal 137 Conservatory of Ghent (Mengal, campus Hoogpoort) - School of Arts Ghent. The violin player 138 was a professional musician. Before the experiment, the violin player only tried the instruments 139 on one occasion one month before the experiment. As each instrument would be played at least 140 two times, which resulted in a total experiment time of 41 minutes, the first experiment was 141 performed with one player. Repeating the entire experiment with a second player was found to be 142 less appropriate, given the fact that the listener's task is quite demanding and there is a risk 143 perceptual fatigue influences the results.

144 First, as requested by the participants, four random instruments (decided by draw) were played 145 (Spruce, UDFlax, TwillCB and Sandwich) to allow the listeners time to get familiar with the 
146 acoustics of the hall and the sound of the prototype instruments. The order in which the

147 instruments were presented for the actual experiment was decided by random draw and was:

148 TwillCA(1), TwillCB, Sandwich, UDFlax, TwillCA(2), Spruce, UDC. TwillCA was presented

149 two times unbeknownst to the audience. If TwillCA scores similar both times, this would be a

150 good indication that a difference between violins can be taken as a difference in the sound

151 produced and not a difference in playing or order effect or fatigue.

152 One after another, with approximately 25-30 seconds in between, each violin was played and the

153 audience was asked to rate the same set of pairs of adjectives for each violin. After the first

154 sequence was completed, the same sequence was repeated. Listeners could indicate their overall

155 preferred, second-preferred and least-preferred instrument, and their preferred instrument

156 regarding warmth, power and richness. For that additional assessment, the audience was given

157 the possibility to hear violins again in pairs of their choice. This resulted in the following

158 additional comparison: TwillCB and UDC; Sandwich and UDFlax; TwillCA(1) and TwillCA(2).

159 It has to be noted that the only violin which was not asked for the additional assessment was the

160 one with a wooden (spruce) top. Additionally, the listeners were asked which adjectives they

161 considered to be most important to judge the sound of a violin. Finally, some details regarding

162 their musical experience were asked as well.

163 During the entire evaluation experiment, the violinist was positioned on stage approximately $1 \mathrm{~m}$

164 behind a lightweight polyester fabric screen. The violin player was blinded with a sleeping mask

165 and the scent of the instruments was covered with a perfume. The instruments were handed to the

166 musician in the predetermined order by a researcher. The lights on stage were dimmed during the

167 test, but left on in the seating area, in order to make sure that the audience could not distinguish

168 the different instruments behind the screen. The violinist played the instruments with her own 
169 bow. As in previous studies the bow is regarded in this experiment as an extension of the player's

170 body $^{12-14}$. She played a musical fragment of her own choice ( 88 seconds) to evaluate the violins,

171 as a musician would normally do when evaluating an instrument. The experiment was recorded

172 for further analysis. The violin player was not questioned during the test, to minimize the time in-

173 between the playing of the instruments. After the test the violin player was asked by the

174 researcher what her favorite instrument was, and if she had any other remarks.

\section{B. Results}

176 First, we examined how the participants described the sound of each violin, based on presented

177 pairs of opposite adjectives. The ratings on each bipolar scale for each violin were compared with 178 a null-hypothesis, using a one-sample t-test with the IBM SPSS $®$ software. The one-sample t-test 179 determines if the population mean is significantly different from a given value or not. This results 180 in a probability value ( $p$-value) providing strong ( $p$-value $<0.05)$ or weak $(p$-value $<0.1)$ evidence 181 of this deviation from the given value. The null-hypothesis $\left(\mathrm{H}_{0}\right)$ was that the audience did not 182 favor one adjective over the other in a pair in order to describe the sound of a violin, which would 183 result in a mean score of 3.5. Strong and weak evidence to reject the null-hypothesis was found 184 for each of the presented violins in a number of cases (Table II). Through this method, adjectives 185 could be objectively linked to the sound of the instruments. performed. This test revealed a statistically significant improvement ( $\mathrm{p}$-value $<0.05$ ) in the rating of TwillCA(2) on four (out of 11) of the bipolar scales powerful - weak (+0.946), loud - quiet 189 (+0.686), bright $-\operatorname{dim}(+0.829)$ and good - bad $(+0.781)$ in comparison to the rating of 
191 Fig. 2 shows the rating for two bipolar adjectives: rich - poor and warm - cold. Rich has been 192 shown to be the most important quality for violinists in a previous study ${ }^{21}$, while warm is often 193 used to describe the sound of conventional wooden violins in comparison to other materials. 194 TwillCB, UDFlax and UDC show large statistic deviations from the expected mean a random 195 distribution would show towards warm. For rich - poor only TwillCB and Spruce show a 196 statistically strong deviation towards rich. The scale from 2 to 5 was chosen as all our calculated 197 means +/- standard error of the mean (SEM) fit within this scale (Appx).

198 Fig. 3 shows the selection of 'best', 'second best' and 'worst' instrument overall. TwillCB and 199 UDFlax were mostly chosen as 'best' (9). UDC was most often chosen as 'second best' (9). 200 Sandwich was chosen most often as 'worst' (12).

201 Listeners were asked which instrument they found "most rich/most powerful/most warm" (Fig. 202 4). Interestingly TwillCA(2) was preferred more than TwillCA(1), this corresponds with a 203 consistently higher mean score on positive attributes like: powerful $(+0.95)$, bright $(+0.83)$, good 204 (+0.78) and loud (+0.69) (Figures Appx). The differences could be explained by the order. 205 TwillCA(1) was the first to be heard, TwillCA(2) came after UDFlax and before Spruce. As 206 UDFlax was never chosen on the question 'Which instrument did you find most powerful?', 207 TwillCA(2) may have appeared more powerful in contrast.

208 Listeners were asked which pair of adjectives they found were "most important to judge the 209 quality of a violin?" (Fig 5). Three of the bipolar pairs were prompted by the previous question 210 "Which instrument did you find most rich/most powerful/most warm", and so listeners might 211 have a positive bias towards these pairs. warm - cold (13) and rich-poor (12) scored higher than 212 powerful - weak (2). This finding can be interpreted as follows: either these listeners find the 213 power of the sound of a violin secondary to the sound color, or they could have (either 
214 intentionally or unintentionally) favored sound color over power in an effort to rate attributes 215 which are thought to be related to wood. The pairs loud - silent, harsh - soft and good - bad 216 were never written down and are therefore not included in Figure 5.

217 When we examine the Root-Mean-Square (RMS) level of the audio recording made during the 218 evaluation experiment (Fig. 6a) the Sandwich violin stands out with the highest RMS level. RMS 219 level is a measure of the average value of a waveform over time and is an approximation of the 220 acoustic sound level perceived by our ears. The violins with a top plate made from a material 221 with a higher degree of anisotropy: UDC, UDFlax and Spruce have a slightly lower RMS value 222 compared to the other violins. To rule out the effect of the player, additional acoustic radiation 223 measurements of the violins were performed with an impact hammer in a anechoic chamber (Fig. $2246 b$, more info in appendix). These measurements show that the Sandwich violin is the most 225 effective sound radiator between approximately 400 and $4000 \mathrm{~Hz}$. UDFlax is the least effective 226 sound radiator between the measured violins above $400 \mathrm{~Hz}$. Below $400 \mathrm{~Hz}$, the violins with a 227 soundboard made from unidirectional composites, UDC and UDFlax, have the highest average 228 acoustic response.

229 The violin player's favorite was the Sandwich violin because it was "easy to produce a lot of 230 sound". Her least favorite was UDFlax because she "felt she had to work very hard on the 231 instrument". The violin player had a suspicion that violins 1 and 5 were the same instrument, 232 which was the case (TwillCA).

\section{IV. THE SELECTION EXPERIMENT}

234 A. Methodology 
235 The musician, the acoustics of the hall and the procedure of the evaluation experiment have 236 surely affected the results of our first experiment. Especially a significant order effect was 237 observed in our measurements, which makes the interpretation of the results more difficult and 238 limits the possibility to draw conclusions. Therefore, we conducted a second listening experiment 239 to verify whether similar trends could be observed with a different protocol, based on pairwise 240 comparisons. To limit the fatigue of the listeners, the number of comparisons should not be too 241 large, which reduces the number of instruments that can be used. Three violins from the first 242 experiment were selected: UDFlax, TwillCB and Sandwich. Both UDFlax and TwillCB were 243 preferred in the first experiment, while Sandwich was evaluated most often as "worst" violin.

244 It is presumable that listeners perceive and judge the sound of a violin in relation to all other 245 presented instruments. As the composite violins sound rather different from conventional violins, 246 one could argue that the listeners' perception of these violins could be affected if a conventional 247 violin was presented during the same test and that our results would only hold in the particular 248 context of these prototype violins. An additional wooden instrument was therefore added in this 249 experiment. The violin was a Stradivarius model made by the same luthier and was set-up with 250 the same bridge, strings, tailpiece, chinrest and pegs as the other composite instruments. Sound 251 radiation measurements (Fig. 6b) show how this conventional violin has a very different 252 frequency response function from the prototype violins. Considering that one of the main goals of 253 this study is to link the perceptual evaluations of the composite violins to differences in their 254 construction in order to shed light on traditional instruments manufacturing, the conventional 255 violin was thus only used to ensure the relevance of the listeners' evaluations of these prototype 256 violins when taking into account regular violins as well. Therefore only the pairs comparing two 257 composite violins were analyzed. 
258 In this second experiment, the four violins were presented in pairs to 40 listeners, all members of 259 the Ghent University Orchestra (GUSO). The listeners had an average of 14 years of experience 260 playing music instruments. Fifteen listeners were violin players. The instruments were played 261 behind the same screen as during the first experiment. The selection experiment took place in a 262 200-seat hall Trechterzaal, Therminal, Ghent University.

263 The format of the listening test was based on the one used $\mathrm{in}^{14}$. The test was conducted twice with 264 a different violin player for each part. The violin players were members of the orchestra. To 265 judge each pair of violins, the musicians first played a scale (34 seconds) on each violin, followed 266 by a short piece of music of their own choice (20-30 seconds) on each violin (Appx). This so267 called $\mathrm{ABAB}$ format of the experiment made it possible for listeners to hear each violin twice, 268 that is both before and after the other violin ${ }^{14}$. In this way, each musician presented all the violin 269 pairs in $\mathrm{ABAB}$ format (Table III). Between the two musicians, the order in which the pairs were 270 presented and which violin went first in a pair was changed over the two tests so the order of 271 presentation was balanced (Appx). In the questionnaire, the listeners were asked which 272 instrument they preferred and why. Listeners could skip a certain pair if they did not have a 273 preference. Secondly, they were given three quality factors: 'better projection', 'better balance'

274 and 'better sound color'. They were asked to choose any number of those quality factors that 275 explained why they chose the said violin. If they chose 'better sound color', they could further 276 specify their choice using a list of selected adjectives to describe that sound color in more detail.

277 They had the option to add additional remarks to explain their preference. (Questionnaire Appx).

\section{B. Results selection experiment}

279 As a summary of the results shows in Table III, TwillCB was preferred by most of the listeners over UDFlax with both violin players. Listeners clearly favored TwillCB over Sandwich when 
281 listening to player 1 but did not in the case of player 2. UDFlax was favored over Sandwich in 282 both cases.

283 Listeners based their preference mostly on sound color. Only in the case of Sandwich an equal 284 number of listeners gave projection as their reason of preference (Figure in Appendix). As 285 listeners used the adjectives to further specify why they favored the sound color of a certain 286 violin, they ended up with similar choices of adjectives as in the first experiment. UDflax was 287 described most as warm and round, TwillCB as clear and open, and Sandwich most as powerful, 288 bright and rich and least as warm (Fig.7). Due to the nature of this test, listeners could only 289 describe the sound of the violin they favored; harsh, sharp and nasal are most often interpreted as 290 negative attributes when used to describe the sound of a violin. This explains why they were not 291 often picked as adjectives to describe the sound color of the favorite instrument. As nasal was 292 never picked in our selection experiment, it is not included in the graph.

\section{V. DISCUSSION}

294 In this study, the potential of different composite materials for the soundboards of violins was

295 investigated. Six violin-shaped instruments were built in a controlled setting and investigated in two 296 listening experiments.

297 The presented results describe the listeners' perspective. In the evaluation and selection 298 experiment we investigated which instruments were preferred and how listeners described their 299 sound. Do some project better than others? Do some have a sound color which is more preferred? 300 What possible quality factors are more important to the listeners?

301 As expected, our experiments show that by using a variety of composite materials for 302 soundboards of violins, a wide range of sounds and timbres can be produced. As the use of these 
composite materials allow violin makers to change the sound of a violin in a number of ways, 304 they can offer new artistic opportunities for violin players and composers to explore. Therefore, 305 these findings could have implications for the future development and production of music 306 instruments as well as future musical compositions and performances.

307 The low ratio of stiffness/density of the flax composite material resulted in a higher weight for 308 the finished soundboard in comparison to the other materials. In the acoustic radiation 309 measurements, UDFlax was the least effective sound radiator between our violins. It is therefore 310 not surprising that the instrument was the least associated with attributes linked to loudness, such 311 as powerful and projection. Our results confirm the theory ${ }^{22}$ that a material with a lower ratio of 312 stiffness/density and higher damping is a less efficient sound radiator, resulting in a less powerful 313 or loud sound. Although this instrument was the least favored by our violin player in the 314 evaluation task, it was preferred by many listeners for its warm and round sound color.

315 The instrument made from a lightweight, low damping and low anisotropy sandwich material 316 consisting of carbon and an aramid honeycomb (Sandwich) was mostly chosen as most powerful, 317 had the highest mean for loud, had the highest RMS value and sound radiation measured and was 318 the only instrument being favored largely for its projection. Yet this instrument was the least 319 preferred in our evaluation task and least picked as favorite in our selection task when played by 320 the first violin player, but was more liked when played by the second player. These findings are 321 in line with a previous study ${ }^{14}$ showing that violins with the best projection are not always chosen 322 as favorite by listeners. Listeners' evaluations can be influenced by the performer's way of 323 playing the instrument. In our evaluation experiment, this violin's sound color was described as 324 harsh. This is less clear in our selection experiment, as the nature of this experiment emphasizes 325 the positive qualities of each instrument. 
327 was chosen less as powerful. This could be an indicator that for composite materials, a higher 328 degree of anisotropy results in an instrument with a round and soft tonal color preferred by many 329 listeners, but with a less powerful sound. This is in line with the simulations performed by Viala ${ }^{23}$ 330 that showed variations in anisotropy to have a significant effect on certain modes of the violin. 331 Indeed, the modes for which the radial direction is important will have a lower frequency and 332 more damping when the radial stiffness (Er) is lower (which is the case when the anistropy is 333 high), which intuitively goes well with a less powerful but rounder sound. More research is 334 definitely needed to investigate this aspect and correlate it with numerical predictions.

335 In our evaluation experiment, two violins were preferred more than others. One had a soundboard 336 from a laminate of unidirectional and woven carbon (TwillCB), the other was made from 337 unidirectional flax (UDFlax). Although UDFlax had the least powerful sound among our 338 prototypes, its sound color being described as warm, soft and round still made it a favorite for 339 many listeners. The other favorite instrument TwillCB had a sound color described as warm and 340 rich. In our selection experiment, TwillCB was favored over UDFlax by the listeners with both 341 players. The listener's preference in our experiments seem mostly guided by sound color, and 342 less by projection or loudness of the instruments. However, when both instruments have a 343 favorable sound color, the instrument with the better projection was favored between the two 344 most preferred violins. In both experiments, listeners indicated to find a warm sound an important 345 quality parameter, followed by adjectives such as clear, open, round and rich.

346 When we compare the results from TwillCA to TwillCB, the two instruments with identical top 347 plate materials, it is clear that the instruments were rated differently in our evaluation task. More 348 research is needed to understand what is the cause of these differences. When we examine the 
scores of TwillCA(1) and TwillCA(2) we observe some differences in attributes that are linked to

350 loudness like powerful or loud. A possible explanation for this finding is that TwillCA(2) was 351 presented after UDFlax, the least powerful and loud instrument. As the listeners had just heard 352 UDFlax, they rated TwillCA(2) in relation to this, resulting in a different score in adjectives 353 related to projection. As TwillCA(1) was the first violin played, it could have been affected by 354 the order in which the instruments were presented. The order effect of the sequence on the rating 355 of violins is not well documented in literature. Research on judge bias in the Idol series shows 356 that in a sequence of seven, the score of the first contestant has the highest negative mean bias ${ }^{24}$. 357 As such, it is feasible that TwillCA(1) was affected by a negative bias due to the order effect.

The instruments presented in this study differ from a classic violin in a number of ways, therefore 359 we cannot directly extrapolate the results from our violin with a spruce soundboard to that of 360 wooden violins in general. We can only say that between our prototypes, the violin with a spruce 361 soundboard was not favored over the full-composite violins and did not stand out in a particular 362 way with regard to tonal color or projection. Future research has to be performed in order to 363 allow for more direct comparisons between instruments with composite top plates and truly 364 conventional, wooden violins. An alternative road future studies could take is to investigate the full-composite instruments as a class of sound-generators of their own, with their own sonic possibilities, and be less concerned about a comparison with their conventional counterparts.

As the experiments presented investigate the sound of these violins from a listener perspective, 368 the perception of these violins by violin players is outside the scope of this study. As the 369 preference of the violin player in our first experiment was the exact opposite of the trend shown 370 by the listeners, it is evident this must be examined further in future experiments. Additionally, 371 examining how these instruments are perceived when they are accompanied by an orchestra or 
372 played in an ensemble can provide valuable psychoacoustic insights. Finally, the vibro-acoustical

373 behavior of these violins could be further examined through modal analyses, which would give a

374 deeper understanding on the effect of the material properties on the body shell response of music

375 instruments.

\section{VI. CONCLUSION}

377 Contrary to popular opinion among violin players, there is no specific sound property or quality 378 that we can assign to the material group of fiber reinforced composites. As a consequence no 379 generalizations like 'the sound of carbon violins lack warmth' hold in our experiments. 380 Composite materials allow to create violins with a large diversity in sounds and therefore offer 381 possibilities to change the sound to the criteria of the player. In theory, by only varying the 382 material of the soundboard, the sound of a violin could be changed to fit the requirements of the 383 player. Our results follow the logic that soundboards which are more lightweight and have a 384 lower anisotropy are more efficient sound radiators than heavier soundboards with a higher 385 anisotropy. However, the influence of more or less anisotropy on the energy output should be 386 further investigated, as this study only had a limited amount of instruments to compare and draw 387 conclusions from.

388 Although all our participants can be considered experienced listeners, individuals prefer different 389 violin-like sounds. Depending on which violin player is playing, the preference of the listener can 390 shift between instruments. Although the sound of some violins was favored more than others, 391 there was no such thing as the 'best' violin sound overall. 
392 Our results indicate that when violins are played consecutively the order effect is large. 393 Violinmaking or playing competitions, should adapt their methodology accordingly to ensure a 394 fair evaluation of each violin or musician.

395 This research provides insight in how violins with soundboards from different composites can 396 sound, the possible advantages these materials can offer in relation to the sound they produce as a 397 soundboard for violins, and which of these violins were favored by listeners. However, composite 398 materials offer a great diversity of fibers, polymer matrix and core materials that must still be 399 examined. While the craftsmanship of making good wooden violins has evolved over centuries, 400 resulting in an optimization of the realization of the material's potential. Composite instruments 401 are very new and may require a new kind of craftsmanship in order to obtain optimal results. 402 Composite instruments commercially available today might need more development in order to 403 realize the full potential of these new materials. More research is needed if we wish to discover 404 more regarding both the potential of composite materials for music instruments, and how to 405 realize that potential.

\section{Acknowledgements}

407 We thank all musicians and listeners who took part in these experiments for their dedication and 408 patience during the experiments. We thank FWO (Research Foundation Flanders grant nr. $4091180217 \mathrm{~N}$ ) for funding this research. Ghent University and Hogent - School of Arts Ghent for 410 providing logistic support. We would like to thank Matthieu Libeert for consulting throughout 411 production of the composite parts using VARTM. Thanks also to Patrick Housen, who recorded 412 the evaluation experiment. Thanks to Lineo for donating FLAXTAPETM that was used to make 413 the UDFlax violin. 
${ }_{414}$ Appendix

415 Information about materials and production method of the violins. The composite violin geometry is

416 based on the dimensions of a conventional violin model (Table I), but adapted to facilitate fabrication

417 using a mold. The height of the ribs is $30 \mathrm{~mm}$.

418 Table I: Dimensions of the top plate used for the violin prototypes.

\begin{tabular}{|l|l|}
\hline Top plate dimensions & Dimensions $(\mathrm{mm})$ \\
\hline Length & 356 \\
\hline Width upper bout & 165 \\
\hline Width center & 107 \\
\hline Width lower bout & 206 \\
\hline
\end{tabular}

419 The bodies (back, sides and neck) were made from twill woven mats of carbon fiber reinforced polymer

420 (CFRP) produced by vacuum assisted resin transfer method (VARTM). The carbon fiber used was

421 AKSACA ${ }^{\mathrm{TM}}$ A-38, 200 tex (3k) the matrix was EPIKOTETM Resin MSG ${ }^{\mathrm{TM}}$ RIM 135 mixed in a 100:30

422 weight ratio with EPIKURE ${ }^{\text {TM }}$ Curing Agent MGSTM RIMH 137. After VARTM the CFRP was post-

423 cured in a curing oven following the specifications of the manufacturer. After production the quality of the

424 carbon fiber bodies were visually inspected for quality and consistency in the product. Through this

425 method, 3 pieces were eliminated for further use and additional pieces were made.

426 Table II: Material properties from literature used to calculate the required thickness of the composite soundboards.

\begin{tabular}{|l|l|l|l|l|}
\hline Materials & $\begin{array}{l}\text { Longitudinal } \\
\text { Young's Modulus } \\
\text { El (Gpa) }\end{array}$ & $\begin{array}{l}\text { Transverse } \\
\text { Young's modulus } \\
\text { Et (Gpa) }\end{array}$ & $\begin{array}{l}\text { Density } \\
\left(\mathrm{kg} / \mathrm{m}^{3}\right)\end{array}$ & Source \\
\hline Spruce & $10-14.8$ & $0.36-0.73$ & $382-495$ & Spycher M. (2008) \\
\hline UD Carbon & $118.4-119.13$ & $8.85-10.18$ & 1528.6 & Kersemans M. (2014) \\
\hline UD Flax & $26.6-29.8$ & 3.31 & 1330 & Phillips S. (2011) \\
\hline Woven Carbon & $62.7-68.7$ & $62.7-68.7$ & $1540-1610$ & CES Edupack 2019 \\
\hline $\begin{array}{l}\text { Aramid } \\
\text { Honeycomb }\end{array}$ & 0,0000149 & 0,0000149 & 32.5 & CES Edupack 2019 \\
\hline
\end{tabular}

427 Sources:

428 Spycher M., Schwarze F., Steiger R. (2008) Assessment of resonance wood quality by comparing its

429 physical and histological properties. Wood Sci Technol 42:325-342. 
431 Paepegem W. (2014) Identification of the Elastic Properties of Isotropic and Orthotropic Thin-Plate

432 Materials with the Pulsed Ultrasonic Polar Scan. Experimental Mechanics 54:1121-1132.

433 Phillips S., Lessard L. (2011) Application of natural fiber composites to musical instrument top plates.

434 Journal of Composite Materials 46(2): 145-154.

CES Edupack 2019 19.2.0 (2019) Granta Design Limited, Cambridge, United Kingdom.

As the materials varied in Young's modulus, but needed a similar longitudinal bending stiffness for consistency, the required thickness for each material was calculated based on a thickness pattern usually used in violinmaking. For the spruce top plate this was $3 \mathrm{~mm}$ at its thickest in the center going towards $2.2 \mathrm{~mm}$ at the outer edges. This calculation was done using the eLamX ${ }^{2}$ software package that uses the Classical Laminate Theory. Through this method the thickness pattern for spruce was converted into a longitudinal stiffness pattern (D11) that could be used to calculate the required thickness of each composite material. All soundboards were infused (VARTM) using the same epoxy resin as the bodies (See figure 1). Parts were visually checked for quality and consistency and remade if necessary.

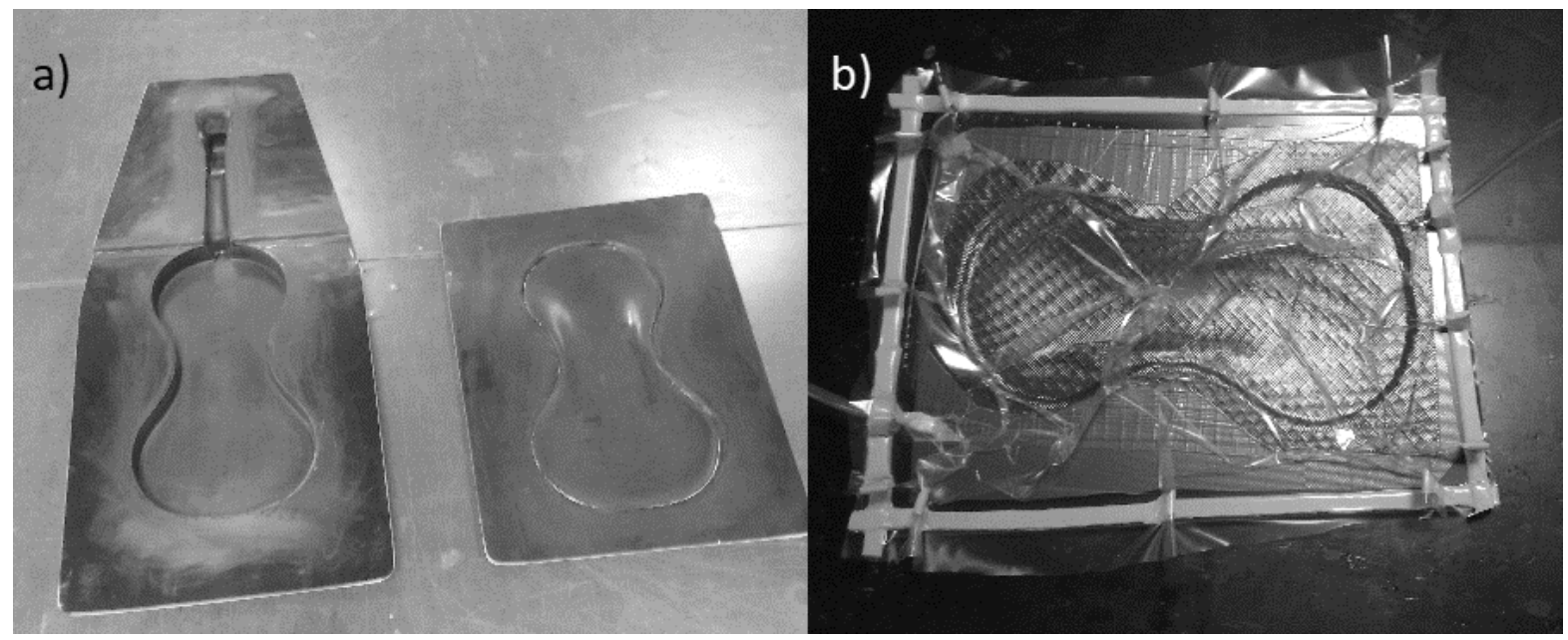

Figure 1 a) Glass fiber moulds for VARTM production of the body and soundboards of the violin. b) Production of a carbon fiber soundboard (UDC) through vacuum assisted resin transfer method (VARTM).

The lay-up for the composite soundboards was the following: 

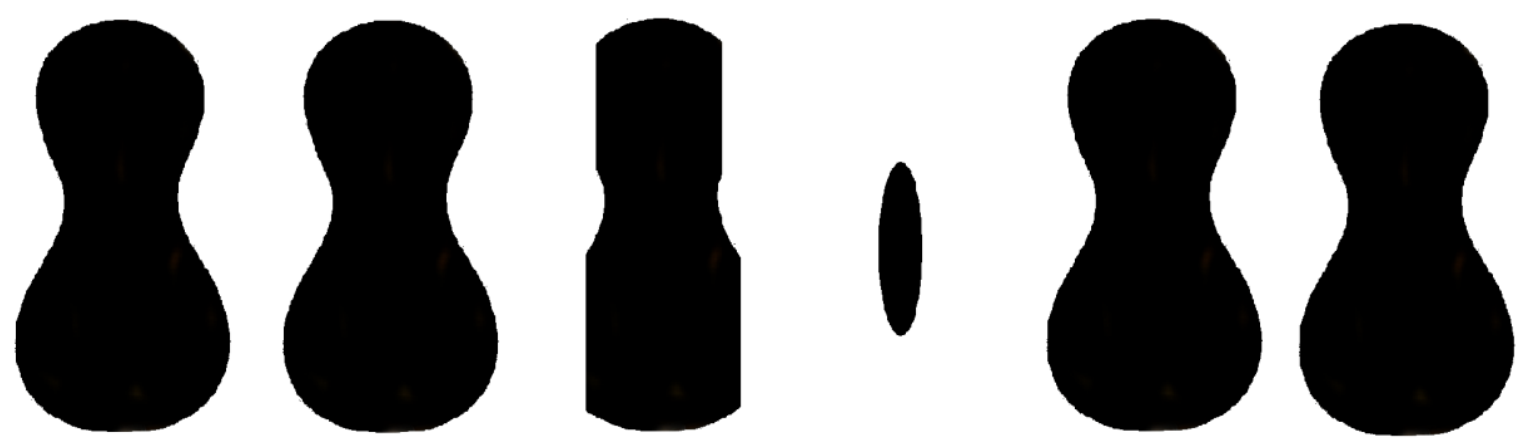

Figure 2: Thickness pattern of the soundboard for TwillC (TwillCA and TwillCB) from left to right: 1 layer Twill-woven AKSACA ${ }^{\mathrm{TM}} A-38200$ tex (3k), 4 layers of unidirectional Tenax ${ }^{\circledR}-E$ HTS40/12K/HS, 1 layer Twill-woven AKSACA ${ }^{\mathrm{TM}} A-38200$ tex (3k).

The design of the sound hole is slightly different than a conventional

violin, but its dimensions fall within standard measurements (Fig. 3).

sound holes were $47 \mathrm{~mm}$ wide and $68 \mathrm{~mm}$ long. Both sound holes were

$42 \mathrm{~mm}$ apart. Nodges were carved up to $9 \mathrm{~mm}$, the widest point without

nodges was $6.3-6.4 \mathrm{~mm}$. The soundboards were fitted with a

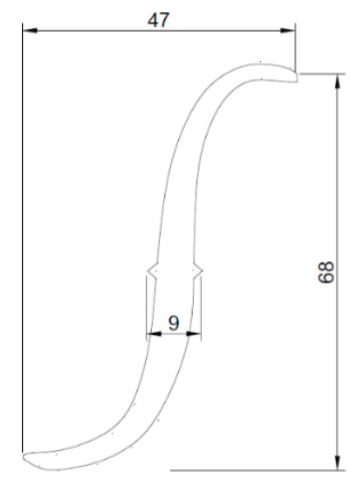

The

469 from the same piece of wood to limit variations in material properties

470 like density, Young's modulus, and shear modulus. All the spruce

Figure 3: Design and dimensions of the soundhole for the prototype violins. 
472 size of the bass bar was conventional with a length of $26.7 \mathrm{~mm}$, thickness of $5.5 \mathrm{~mm}$ at its base and height

473 from $13 \mathrm{~mm}$ at the center on the bridge position towards $3 \mathrm{~mm}$ at the end. String length from the upper nut

474 to the bridge is a standard $328 \mathrm{~mm}$, height of the bridge from the soundboard to the highest point of the

475 bridge was $32-33 \mathrm{~mm}$. The strings on all violins were: Dominant $\mathrm{g}$ (133 medium synthetic core, silver

476 wound), d (132a medium synthetic core, silver wound), a (131 medium synthetic core, aluminum wound)

477 produced by Thomastik-Infeld GmbH (C) and Kaplan e (k420B-3 medium tinned carbon steel core)

478 produced by D’Addario \& Company, Inc. ( $)$

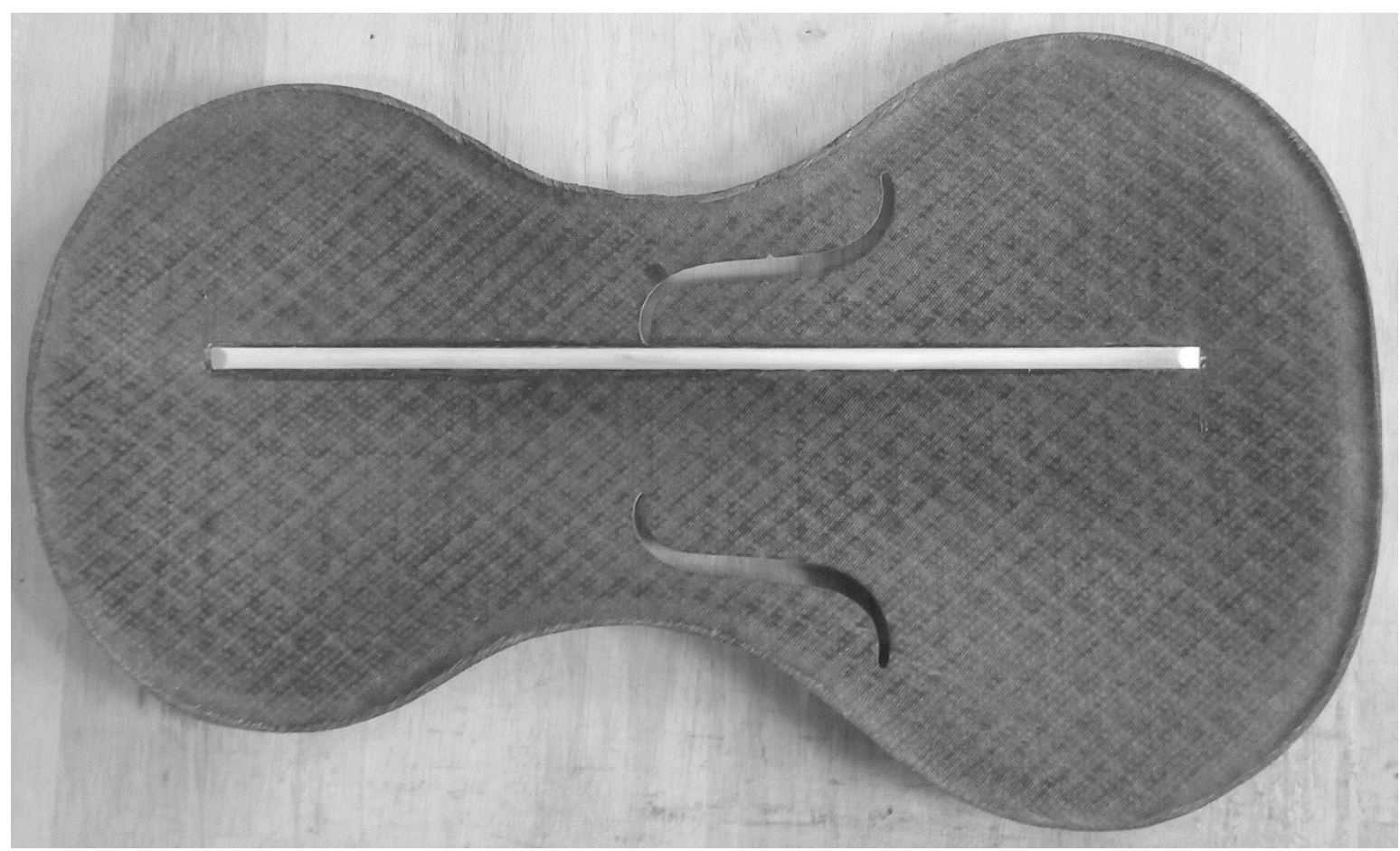


Table III: Total weight of the finished violin prototypes.

\begin{tabular}{|l|l|}
\hline & $\begin{array}{l}\text { Total weight of the } \\
\text { violins (including strings } \\
\text { and chinrest) }(\mathrm{g})\end{array}$ \\
\hline Spruce & 418 \\
\hline UDC & 411 \\
\hline Sandwich & 396 \\
\hline UDFlax & 452 \\
\hline TwillCB & 417 \\
\hline TwillCA & 415 \\
\hline
\end{tabular}

482

483 Damping measurements are derived from the modal analysis of beams cut along (longitudinal, 1)

and across the fibers (transversal, $\mathrm{t}$ ) through impact excitation in the center of the beam and

response measurement with 3 Polytec PSV 500 laser Doppler vibrometer directed at the left,

middle and right side of the beam respectively (Table IV). Only the quality factor of the first

lower damping.

Table IV Measured quality factors of beams cut along $(l)$ and across $(t)$ the fibers, from four spruce plates and six composite

material plates produced by VARTM

\begin{tabular}{|l|l|r|}
\hline Material & & $\begin{array}{l}\text { Quality } \\
\text { factor }\end{array}$ \\
\hline & & \\
\hline Spruce 1 & 1 & 120 \\
\hline & t & 56 \\
\hline Spruce 2 & 1 & 154 \\
\hline & t & 56 \\
\hline Spruce 3 & 1 & 170 \\
\hline & t & 59 \\
\hline Spruce 4 & 1 & 86 \\
\hline & t & 52 \\
\hline & & \\
\hline Flax UD 1 & 1 & 83 \\
\hline & t & 32 \\
\hline
\end{tabular}




\begin{tabular}{|l|l|r|}
\hline Flax UD 2 & 1 & 98 \\
\hline & $\mathrm{t}$ & 44 \\
\hline & & \\
\hline Carbon UD 1 & 1 & 946 \\
\hline & $\mathrm{t}$ & 87 \\
\hline Carbon UD 2 & 1 & 570 \\
\hline & $\mathrm{t}$ & 102 \\
\hline & & \\
\hline $\begin{array}{l}\text { Carbon UD/ } \\
\text { Woven }\end{array}$ & 1 & 641 \\
\hline & $\mathrm{t}$ & 491 \\
\hline & & \\
\hline $\begin{array}{l}\text { Honeycomb/ } \\
\text { Carbon woven }\end{array}$ & 1 & 179 \\
\hline & $\mathrm{t}$ & 189 \\
\hline
\end{tabular}

\section{Additional information on the sound radiation measurements.}

Sound radiation measurements were performed in an anechoic

497 chamber to reduce noise and the influence of room acoustics. The

498 violin was mounted on a rig and excited with a miniature impact

499 hammer (PCB 086E80), acoustic response was measured with a

500 microphone (DPA 2006-C) at a distance of $33 \mathrm{~cm}$ from the bridge.

501 The instrument was measured in 12 positions, with a $30^{\circ}$ clockwise

502 turn of the horizontal plane between each position. The

503 measurement for each position consisted of 3 excitations, of which

504 a complex average was calculated. The coherence function was

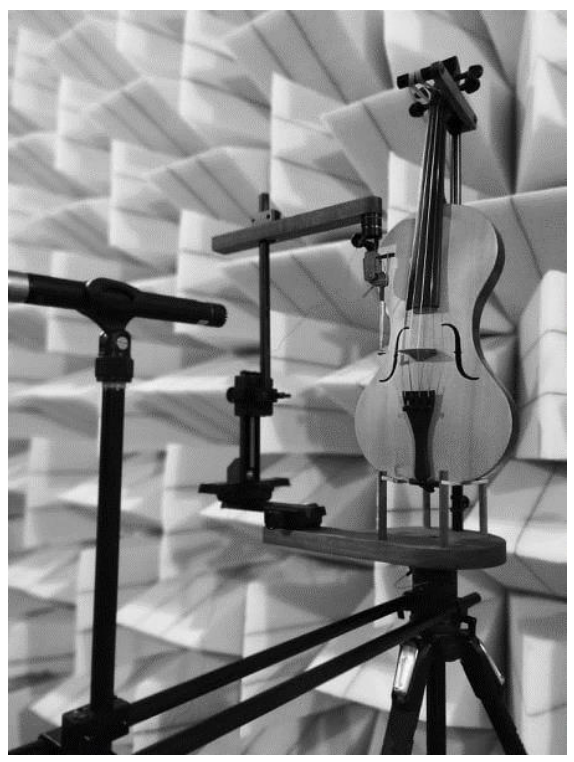

used as a quality parameter, if the coherence was not consistently close to 1 the measurement was repeated. The entire measurement was performed with both horizontal (on the side of the bridge) and vertical excitation (on the top of the bridge). The Oberlin Acoustics App (ObieApp1.0b71) was used as acquisition software, which runs on a LabView platform. 
511 In the evaluation experiment, the violin player chose to play a modified piece of Symphony Espagnole by

512 Édouard Lalo. In specific she chose part 4, pg 1, and modified it so that each string was played for 513 approximately the same time. The excerpt played was approximately 88 seconds at its longest. All 514 excerpts played were recorded with two Zoom H4N - Neuman microphones (km184NI). One microphone 515 was placed approximately $1 \mathrm{~m}$ behind the screen, the other approximately $4 \mathrm{~m}$ further in the room. The 516 recordings are_available for other researchers on request, please contact the main author. In the selection 517 experiment, the two violin players first played a 3 octave scale starting from $\mathrm{G}_{3}$ on each violin (34 518 seconds), followed by an excerpt of their choice from the $9^{\text {th }}$ symphony by Antonin Dvořák (due to 519 practical limitations this experiment could not be recorded).

520 Additional results of the evaluation experiment:

521 In addition to the fixed questions, listeners were also given the option to add other words or remarks on 522 the sound of each violin. They left a total of 49 other remarks, the option was left blank 210 times. 30 of 523 these remarks described the balance being good or bad and/or described particular strings or registers. No 524 other trends were observed in the other 19 remarks.

525 Listeners could indicate which instrument they would like to take-home, no large differences with the 526 question what instrument is best were observed: UDFlax (9), TwillCB (7), TwillCA2 (6), Spruce (5), 527 UDC (3), Sandwich (3) and TwillCA1 (2).

528 Figures showing the rating of the violins in evaluation task (mean $+/-1$ standard error of the mean).

529 Filled brown dots indicate a statistically strong deviation (p-value<0.05) from the expected mean (3.5).

530 Filled yellow dots indicate a weak deviation (p-value $<0.1)$. 
5

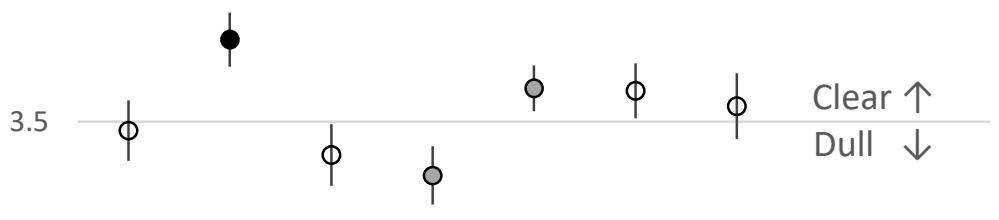

2

532

TwillCA(1) TwillCB Sandwich UDFlax TwillCA(2) Spruce UDC

5
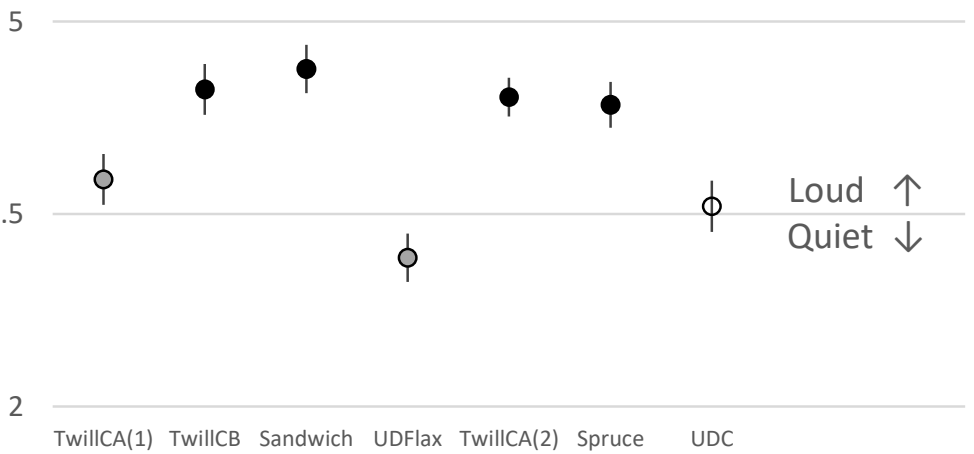

533

5

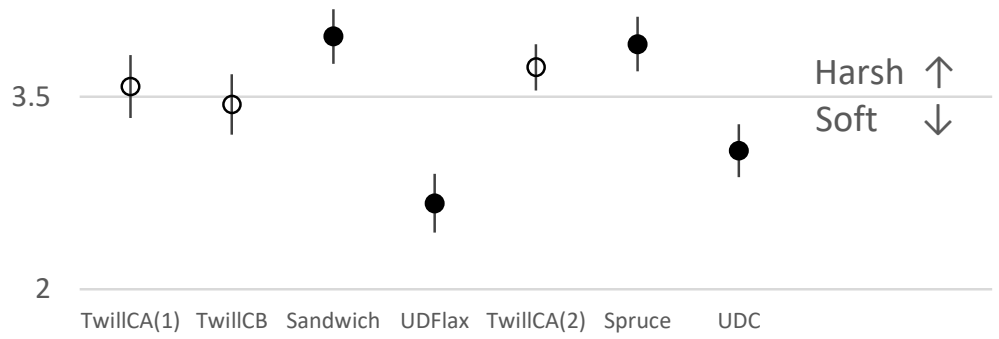

534

27 
5

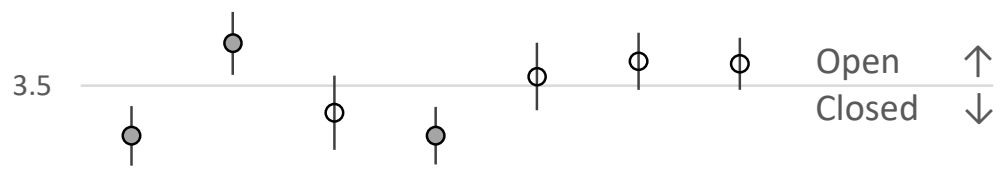

2 TwillCA(1) TwillCB Sandwich UDFlax TwillCA(2) Spruce UDC

535

5

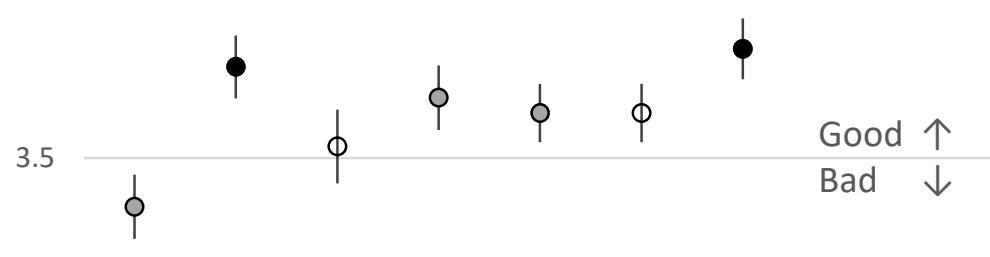

2 TwillCA(1) TwillCB Sandwich UDFlax TwillCA(2) Spruce UDC

536

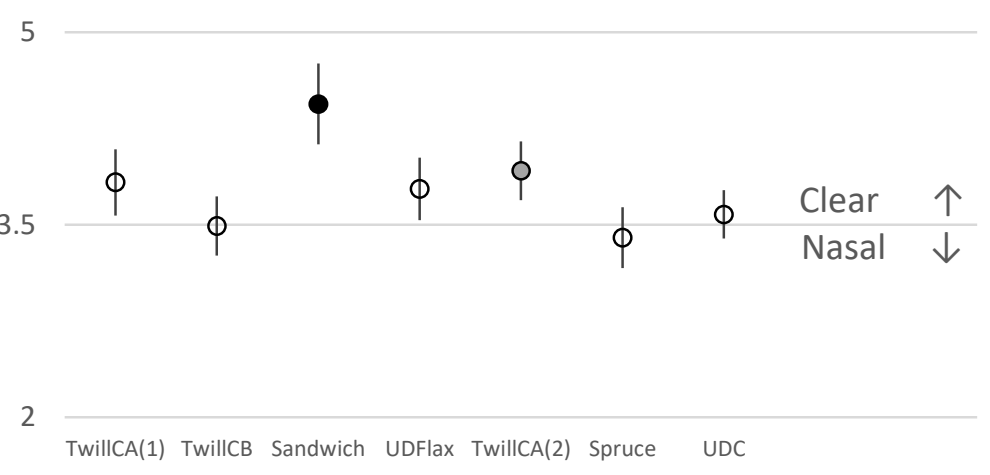


5

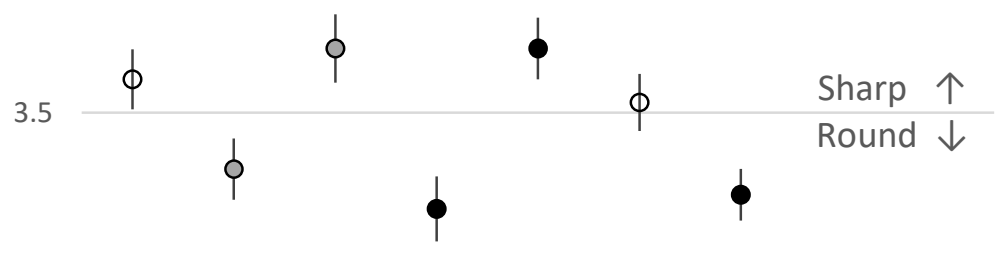

2

TwillCA(1) TwillCB Sandwich UDFlax TwillCA(2) Spruce UDC

538

5

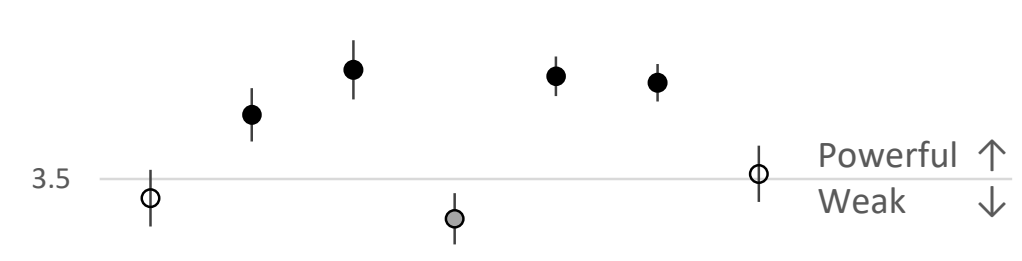

2 TwillCA(1) TwillCB Sandwich UDFlax TwillCA(2) Spruce UDC

539

540

5

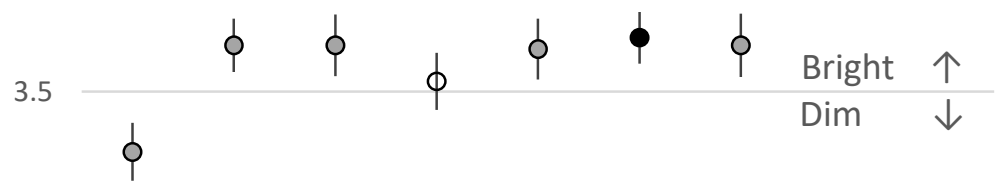

2

TwillCA(1) TwillCB Sandwich UDFlax TwillCA(2) Spruce UDC

542 Figure 6: Mean score +/- SEM of the violins on the pairs of adjectives presented on a 8-point Likert scale. Filled black dots 543 indicate a statistically strong deviation ( $p$-value $<0.05)$ from the expected mean (3.5 dotted line). Filled grey dots indicate a 544 statistically weak deviation ( $p$-value $<0.1$ ). 
545 Order of presentation selection task. The order in which the different pairs were presented and their 546 subsequent order was for Player 1: Conventional violin - TwillCB; Sandwich - Conventional violin; 547 TwillCB - UDFlax; Conventional violin - UDFlax; TwillCB - Sandwich; UDFlax - Sandwich. Violin 548 player 2: Sandwich - TwillCB; Conventional violin - Sandwich; UDFlax - TwillCB; Sandwich 549 UDFlax; TwillCB - Conventional violin; UDFlax - Conventional violin.

\section{Additional results of the selection experiment.}

551 In the selection experiment, listeners were asked to indicate why they chose a particular violin. As some

552 violins were chosen more often than others, these are displayed in percentage to the amount of times a

553 violin was chosen in figure 7.

554

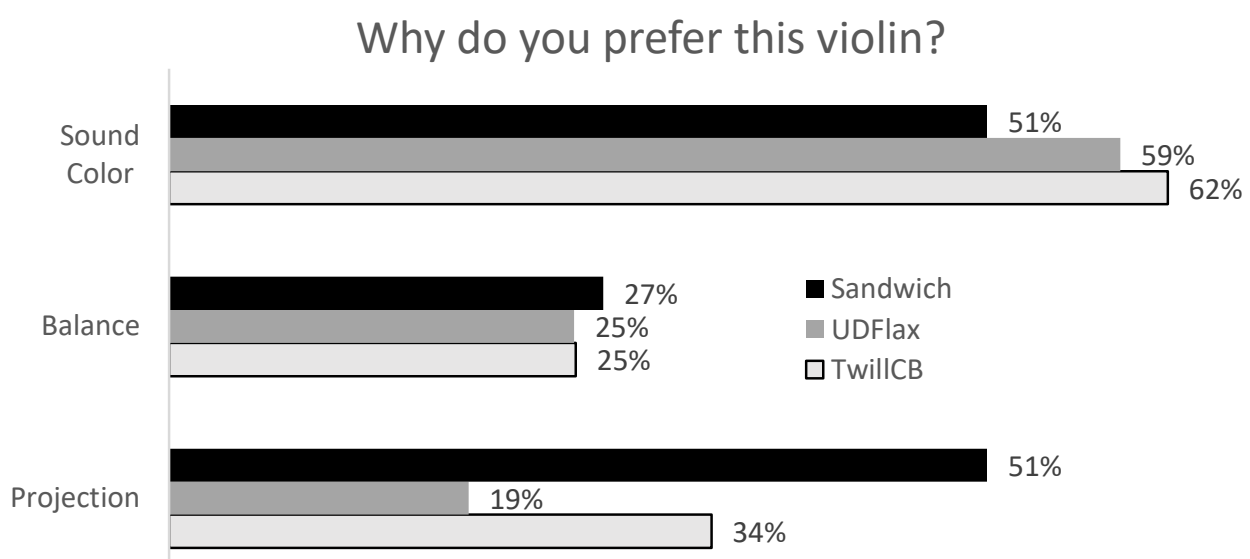



order. You will listen multiple times to respectively violin 1, 2, 3, 4, 5, 6, and 7.

On the following pages you will find an evaluation sheet for each violin, on which you will give your opinion on how the instrument sounds for you. Pay attention! The pages are printed recto-verso. On the last page you will find some general questions about the instruments and your personal background. Please take care to fill in everything, otherwise your contribution can not be used for the research. a preference between the two words you select the box 'I don't know'.

570 If you don't understand something or have questions about how to fill out this questionnaire, please ask before the start of the experiment.

571 After the experiment the instruments will be revealed, then there is time and space for questions and discussion. This questionnaire is personal,

572 please fill it out on yourself. If you don't know or if you don't have an opinion you can always select or write this.

573 You will give your answer on the scales with a dot on one of the vertical lines. With this questionnaire you will also receive a separate sheet on

574 which more information about the different words is given.

575 Here are some examples on how to fill in the scale using the example of tasting different apple pies.

577 I think apple pie 1 tastes very sweet, so I put a dot at the extremity of the direction sweet.

579 know

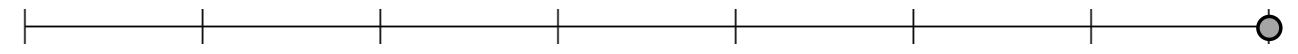
dot on the scale to indicate this. 
585 know

586

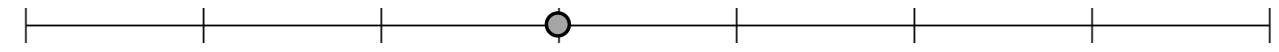

587

588

I don't know if apple pie 3 is more sour or sweet. I put a dot in the box 'I don't know'.

589 Sour

Sweet

I don't

590 know

591

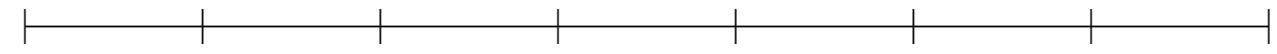

592

593 If you wish, you can indicate a preliminary opinion with a line above the scale, before later putting a dot

594 somewhere on the scale.

595 
599 know

600

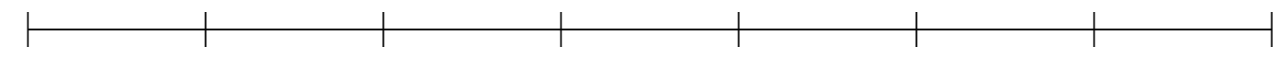

601 Round

Sharp

don't

602 know

603

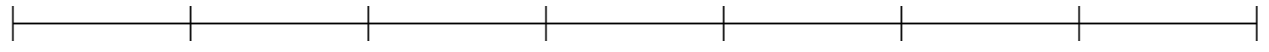

604 Quiet

Loud

don't

605 know

606

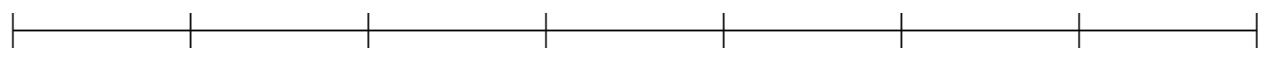

607 Cold

Warm I don't

608 know

609

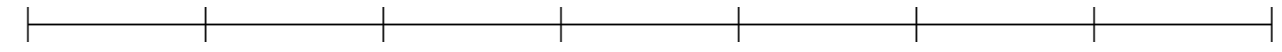

610 Harsh

Soft I

don't

611 know

612

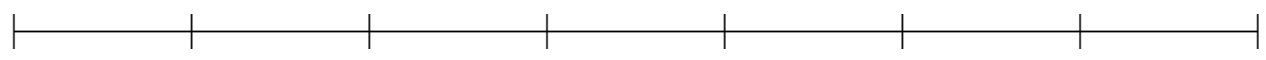

613 Powerful

Weak I don't

614 know

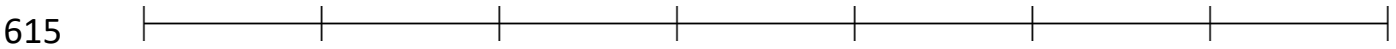

$616 \mathrm{Bad}$

Good

don't

617 know

618

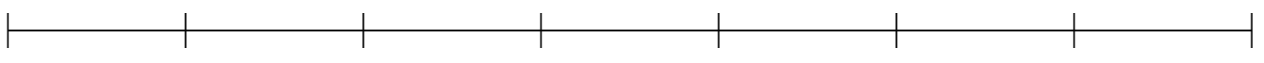




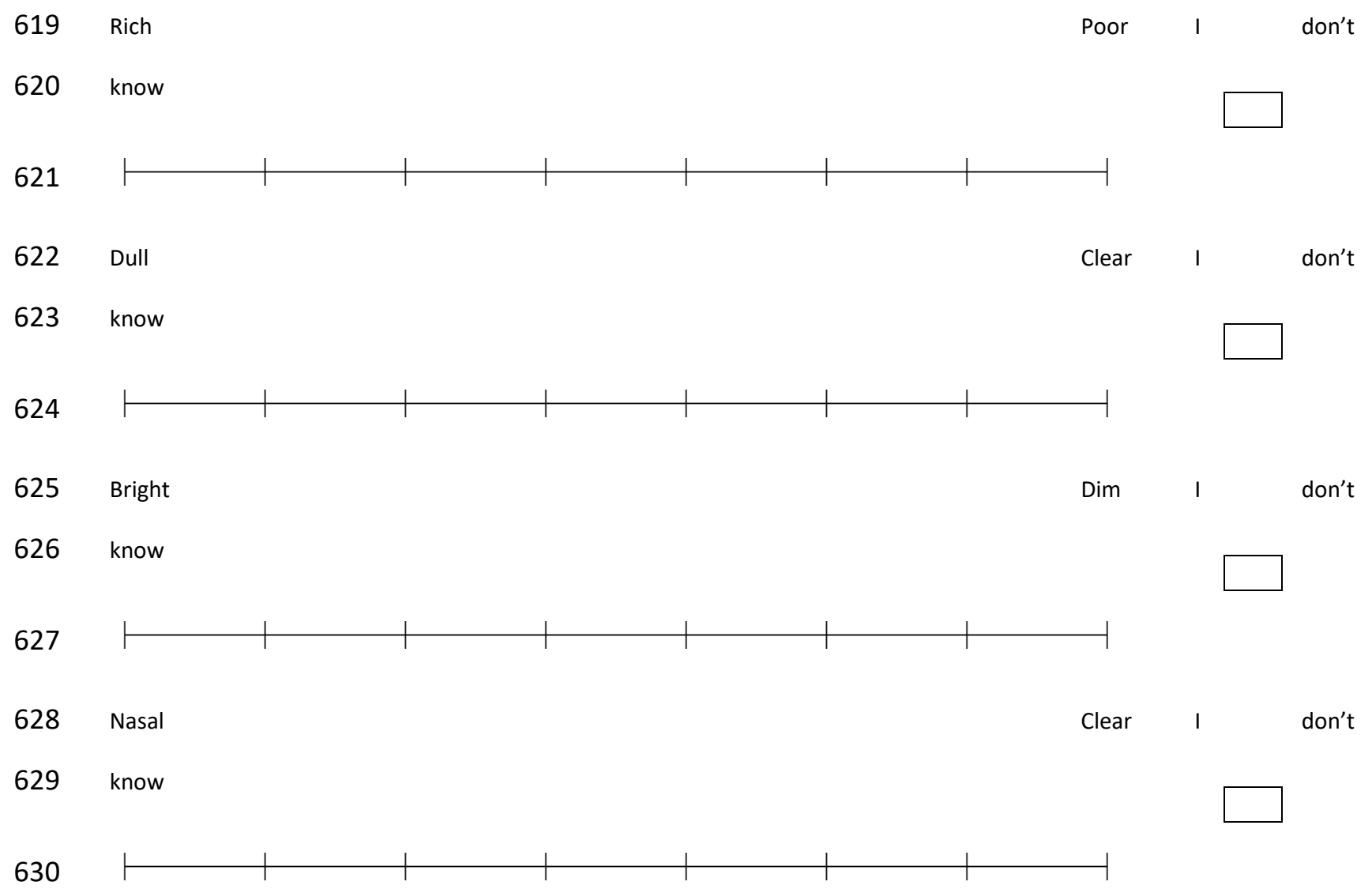

631

632

633 Do you have other words or remarks on the sound of this instrument?

634

635

${ }_{636}$ General questions

637

638 The best instrument is in my opinion $\mathrm{Nr}$ :

639 The second best instrument is in my opinion $\mathrm{Nr}$ :

640 The worst instrument is in my opinion $\mathrm{Nr}$ : 
641 Which instrument(s) do you think have a wooden soundboard? $\operatorname{Nr}(s)$ :

642 Which instrument did you find most warm sounding?

643 Which instrument did you find most powerful sounding?

644 Which instrument did you think most rich sounding?

645 What pair of words do you think is most important to judge the quality of a violin?

646

647 How does a violin have to sound for you to be selected as best?

648

649

650 If I could take an instrument home I would take Nr:

651

652 Put a circle around what fits best:

653 I am a: student instrumentenbuilding student classical music teacher researcher other

654

655 Do you regularly play an instrument?

656

657

If yes, what/which instrument(s) do you play?

658

659

If yes, for how many years have you played an instrument? 
English:

664

665

666

667

668

669

670

671

672

673

674

675

676

677

678

679

680

681

682

683

684

685

686

687

688

689

690

691

692

693

694

695

696

697

698

699

700

701

702

703

704

705

706

707

708

709

open

loud

warm

clear

sharp

nasal

harsh

rich

bright
Description: free, loose

Contradiction: closed

Description: a great volume in sound.

Comparison: shouting is loud, whispering is silent.

Contradiction: quiet

Description: with depth.

Comparison: some radio-presenters, often on

late-evening broadcasts, have a very 'warm' voice.

Contradiction: cold

Description: without noise, lucid, light, pure.

Contradiction: dull

powerful

Description: strong, overwhelming, muscled

Contradiction: weak

Description: cutting, pointy, penetrating

Contradiction: round

Description: nose sound

Comparison: someone who talks with a

closed nose, or sound that are carried through

the nose like ' $n$ ' and ' $n g$ '.

Tegenstelling: clear

Description: something that is strongly expressed or pronounced. Solid and firm.

Contradiction: soft

Description: with many harmonic overtones, with a broad and full harmonic spectrum.

Contradiction: poor

Description: with a brilliance, sparkling, virtuoso
Dutch:

open

Beschrijving: vrij, los

Tegenstelling: gesloten

luid

Beschrijving: een groot volume in klank.

Vergelijking: Roepen is luid, fluisteren is stil.

Tegenstelling: stil

warm

Beschrijving: met veel diepte.

Vergelijking: sommige radio-presentatoren,

vooral op Klara en in laatavond programma's, hebben een zeer

'warme' stem.

Tegenstelling: koud

helder

Beschrijving: duidelijk en zonder bijgeluiden, klaar, licht, zuiver.

Tegenstelling: dof

krachtig

Beschrijving: sterk, overweldigend, gespierd

Tegenstelling: zwak

scherp

Beschrijving: snijdend, puntig, doordringend

Tegenstelling: rond

nasaal

Beschrijving: neusklank

Vergelijking: iemand die met een afgesloten neus praat, of klanken die door de neus naar buiten worden gedragen zoals ' $n$ ' en 'ng'

Tegenstelling: helder

hard

Beschrijving: iets dat sterk uitgedrukt of uitgesproken is.

Vast en stevig.

Tegenstelling: zacht

rijk

Beschrijving: veel harmonische boventonen, met een breed en vol spectrum

Tegenstelling: arm

briljant

Beschrijving: Met een schittering, fonkelend, virtuoos 


\section{Questionnaire selection task}

712 Dear participant,

713 Thank you for participating in this blind listening test.

714 For each violin player, you will hear six pairs of violins. Please put a circle around the instrument that

715 enjoys your preference and indicate why you chose this violin as favorite. You can select multiple

716 reasons. If you choose Sound color, please describe it by putting a circle around the words that best

717 describe said sound color for you. If you have other words to describe the sound, you can write these on

718 the dotted line.

719 We will do this experiment with two violin players. The order in which the instruments are presented will

720 be changed between the violin players.

721 If you have any questions regarding this questionnaire please ask them before the start of the

722 experiment. After the test is concluded the instruments will be revealed and there will be time for

723 additional questions.

726 How many years do you play a musical instrument:

727

\section{Violinist nr. 1}


$730 \quad \bigcirc$ Better projection

$731 \quad \bigcirc$ Better balance

$732 \quad \bigcirc$ Better sound color

warm harsh clear rich open sharp round bright powerful nasal

733 


\section{References / sources}

7361 A. Damodaran, L. Lessard and A. Suresh Babu, "An Overview of Fibre-Reinforced Composites for

737 Musical Instrument Soundboards," Acoust. Aust. 43, 117-122 (2015).

7382 C. Besnainou, "From wood mechanical measurements to composite materials for musical

739 instruments: new technology for instrument makers," MRS Bull, 03 34-36 (1995).

7403 M. Mehdi Jalili, S. Yahya Mousavi and A.S. Pirayeshfar, "Investigating the acoustical properties of

741 carbon fiber, glass fiber, and hemp fiber-reinforced polyester composites," Polym. Compos. 34.

$742 \quad$ (2014).

7434 T. Ono and D. Isomura, "Acoustic characteristics of carbon fibre reinforced synthetic wood for

744 musical instrument soundboards," Acoust. Sci. Technol. 25, 475-477 (2004).

7455 T. Ono and A. Okuda, "Acoustic characteristics of guitars with a top board of carbon fiber-reinforced

746 composites," Acoust. Sci. Technol. 28, 442-443 (2007).

$747 \quad 6 \quad$ S. Webb, "Carbon-fiber cellos no longer playing second-fiddle to wooden instruments."

748 http://www.scientificamerican.com/article/carbon-fiber-cellos (2009). Accessed 22 July 2019

7497 J. Dominy and P. Killingback, "The development of a carbon fibre violin," Proceedings of ICCM-17

$750 \quad$ Conference A 6.2, Edinburgh (2009).

7518 M. Parish, "Perfecting the sustainable guitar," http://www.mmrmagazine.com/81-current-

752 issue/spotlight/389-perfecting-the-sustainable-guitar.html (2013). Accessed 15 Dec 2014.

7539 S. Phillips and L. Lessard, "Application of natural fiber composites to musical instrument top plates,"

$754 \quad$ J. Compos. Mater. 46, 145-154 (2012).

75510 G. Bissinger, "Structural Acoustics of good and bad violins," J. Acoust. Soc. Am. 124, 1764-1773

$756 \quad$ (2008).

75711 C. Fritz and D. Dubois, “Perceptual Evaluation of Musical Instruments: State of the Art and

758 Methodology," Acta Acust. united with Ac. 101, 369-381 (2015). 
75912 C. Fritz, J. Curtin, J. Poitevineau, P. Morrel-Samuels and F.C. Tao, "Player preferences among new and 760 old violins," Proc. Natl. Acad. Sci. USA 109, 760-763 (2012).

$761{ }^{13}$ C. Fritz, J. Curtin, J. Poitevineau, H. Borsarello, I. Wollman, F.C. Tao and T. Ghasarossian, "Soloist

762 evaluations of six old Italian and six new violins." Proc. Natl. Acad. Sci. USA 111, 7224-7229 (2014).

76314 C. Fritz, J. Curtin, J. Poitevineau and F.C. Tao, “Listener evaluations of new and old Italian violin,"

$764 \quad$ Proc. Natl. Acad. Sci. USA 114, 5395-5400 (2017).

76515 See supplementary material at [https://youtu.be/xtSoUKvDGTY] for [a video showing the making 766 process on a violin].

76716 C. Johnson and R. Courtnall, "The Art of Violin Making," Robert Hale, London (1999).

76817 H. Weisshaar and M. Shipman, "Violin Restoration a manual for violinmakers" Weisshaar-Shipman,

$769 \quad$ Los Angeles CA (1988).

77018 eLamX 2.3 Java(TM) SE Runtime Environment, TU Dresden, Dresden. Available at https://tu-

771 dresden.de/ing/maschinenwesen/ilr/Ift/elamx2/elamx (2016). Accessed on 28th of April 2017.

77219 T. Duerinck, “What's the alternative?” The Strad 129, 52-56 (2018).

77320 C. Fritz, A. Blackwell, I. Cross, J. Woodhouse and B. Moore, "Exploring violin sound quality:

$774 \quad$ Investigating english timbre descriptors and correlating resynthesized acoustical modifications with 775 perceptual properties," J. Acoust. Soc. Am. 131, 783-794 (2012).

77621 C. Saitis, B.L. Giordano, C. Fritz and G.P. Scavone, “Perceptual evaluation of violins: A quantitative 777 analysis of preference judgments by experienced players," J. Acoust. Soc. Am. 132, 4002-4012

778 (2012).

77922 U. G. K. Wegst, "Wood for sound," Am. J. of Botany 93.10, 1439-1448 (2006).

78023 R. Viala, Towards a model-based decision support tool for stringed musical instruments making, PhD 781 diss., University of Bourgogne Franche-Comté, France (2018). 


\section{Tables}

Table I: Weight of the finished soundboards, engineering constants calculated using eLamX $X^{2}$ and estimation of damping of the materials. The damping is an approximation in comparison to spruce, which was given the 0 value as the benchmark material.

\begin{tabular}{llllll} 
Soundboard & Weight $(\mathrm{g})$ & $\mathrm{D} 11(\mathrm{Nmm})$ & $\mathrm{D} 22(\mathrm{Nmm})$ & D66 $(\mathrm{Nmm})$ & Damping \\
\hline Spruce & 74.8 & 15.8 & 1.1 & 1.5 & 0 \\
\hline UDFlax & 100.3 & 14.7 & 0.9 & 1.2 & $0 /+$ \\
\hline UDC & 72 & 14.7 & 0.9 & 0.6 & -- \\
\hline TwillCA & 71 & 15.5 & 6.4 & 0.7 & -- \\
\hline TwillCB & 74.8 & 15.5 & 6.4 & 0.7 & -- \\
\hline Sandwich & 42.3 & 15.7 & 15.7 & 0.7 & - \\
\hline
\end{tabular}

Table II: Strong and weak evidence to reject the null-hypothesis and link adjectives to the sound of each of the seven investigated 790 violins.

Strong evidence $(\mathrm{p}$-value $<0.05) \quad$ Weak evidence $(\mathrm{p}$-value $<0.1)$

\begin{tabular}{lll}
\hline TwillCA(1) & $\operatorname{dim}$ & loud, closed, bad \\
\hline TwillCB & $\begin{array}{l}\text { warm, clear, loud, good, powerful, } \\
\text { rich }\end{array}$ & open, round, bright \\
\hline Sandwich & loud, harsh, nasal, powerful & sharp, rich, bright \\
\hline UDFlax & warm, soft, round & $\begin{array}{l}\text { dull, quiet, closed, good, weak, } \\
\text { rich }\end{array}$ \\
\hline TwillCA(2) & loud, sharp, powerful & warm, clear, good, nasal, bright \\
\hline Spruce & loud, powerful, rich, bright & harsh, good \\
\hline UDC & warm, soft, good, round & bright \\
\hline
\end{tabular}

Table III: Preference of listeners for composite violins when presented in pairs during our selection experiment. The pairs with the conventional violin are excluded as these were not a double-blind condition.

\section{Number of participants favoring a specific violin and the} reason why

\begin{tabular}{lrrrr}
\hline Player 1 & $\begin{array}{r}\text { Preference } \\
\text { listeners }\end{array}$ & Projection & Balance & $\begin{array}{r}\text { Sound } \\
\text { Color }\end{array}$ \\
\hline TwillCB & 25 & 13 & 5 & 12 \\
UDFlax & 13 & 2 & 5 & 9 \\
\hline TwillCB & 34 & 13 & 13 & 21 \\
Sandwich & 6 & 5 & 2 & 3 \\
\hline
\end{tabular}




\begin{tabular}{lrrrr}
\hline UDFlax & 24 & 3 & 8 & 17 \\
Sandwich & 14 & 11 & 4 & 5 \\
\hline Player 2 & & & & \\
\hline TwillCB & 29 & 12 & 6 & 18 \\
UDFlax & 8 & 3 & 0 & 5 \\
\hline TwillCB & 18 & 0 & 3 & 13 \\
Sandwich & 20 & 9 & 5 & 9 \\
\hline UDFlax & 22 & 3 & 2 & 12 \\
Sandwich & 16 & 9 & 2 & 9 \\
\hline
\end{tabular}

794

795 


\section{Figure captions}

797

798 Figure 1: Prototype violins with soundboards from 5 different materials constructed for the study. Only

799 one of the TwillC violins is displayed here as the two instruments are visually identical.

800 Figure 2: Mean value (dot) +/- 1 Standard error of the mean SEM (vertical line) of the violins' rating on

801 the attributes warm - cold and rich - poor. Filled black dots indicate a statistically strong deviation (p-

802 value $<0.05$ ) from the expected mean (3.5 dotted line). Filled grey dots indicate a statistically weak

803 deviation ( $p$-value<0.1).

804 Figure 3: Amount of times each violin was chosen as best, second best and worst in the evaluation 805 experiment.

806 Figure 4: Amount of times each instrument was chosen on the question 'Which instrument did you find 807 most rich/most powerful/most warm'.

808 Figure 5: Amount of times a pair of words was written down as important to judge the quality of a violin.

809 In black the pairs prompted by a previous question, in gray the non-prompted pairs. Between the

810 prompted pairs warm - cold and rich - poor, attributes related to the sound color, were chosen

811 significantly more than powerful - weak, an attribute often linked to projection and loudness.

812 Figure 6: a) RMS level of the recording made during the evaluation experiment. b) acoustic sound

813 radiation of all violins measured in an anechoic chamber with impact hammer excitation. Frequency

814 response functions (FRF's) smoothed over one tone for readability and interpretation purposes.

815 Figure 7: Percentage distribution on the description of the favored sound color for each of the violins. 